\title{
Yq deletion with short stature, abnormal male development, and schizoid character disorder
}

\author{
G KOSZTOLÁNYI AND M TRIXLER \\ Departments of Pediatrics and Neuropsychiatry, University Medical School, Pécs, Hungary.
}

SUMMARY A 33-year-old male with short stature, abnormal male sexual differentiation, aspermia, and schizoid character disorder is described, who had a Y chromosome with a deleted long arm. The correlation of the symptoms, including the psychotic abnormality, with the cytogenetic finding is discussed.

According to previous studies correlating clinical and cytogenetic findings in cases with deletion of the long arm of the $\mathrm{Y}$ chromosome, the following genes are assumed to exist on the euchromatic region of $\mathrm{Yq}$ : those influencing spermatogenesis (adjacent to the Yq heterochromatin), those responsible for body growth (proximal to those for spermatogenesis), and male determining genes (close to the centromere). ${ }^{1-3}$ This paper presents a male patient with short stature, abnormal male sexual differentiation, and schizoid character disorder who had a Y chromosome with a deleted long arm.

\section{Case report}

The patient, a 33-year-old male, was the eighth child of healthy parents. At the time of his birth, the mother was 35 and the father 46 years old. The seven other children are healthy with normal intelligence. At birth the patient had to be resuscitated; his weight

Received for publication 22 February 1983 Accepted for publication 16 March 1983. was 2000 g. In childhood he was withdrawn and speech development was grossly impaired. At the age of 10 he was admitted to hospital because of severe autism and regression. At this age his mental development was at the level of a 3-year-old child. He was educated in a special school for the mentally retarded. Since the age of 17 he has been working as an unskilled worker. He was admitted to a psychiatric department because of panic fear at the age of 33 years.

Physical examination revealed a height of $160 \mathrm{~cm}$, moderate fat accumulation on the hips, hypogonadism, feminine distribution of pubic hair, gynaecomastia, scanty facial hair, acne on the face, and a moderate dorsal kyphosis. Psychologically he is characterised by severe autism with inhibited conduct, anxiety, profound distrust of his environment, disturbed social skills, and poor emotional responsiveness. He is mentally subnormal with an IQ of 77 (Weschler). EEG showed a slightly slow electrical activity. PEG revealed slight enlargement of the ventricular system and of the subarachnoid spaces.

Laboratory data were normal except for plasma testosterone $7.2 \mathrm{nmol} / 1$ (normal range 7.6 to 34 ), LH $100 \mathrm{mU} / \mathrm{ml}$ (2 to 20$)$, prolactin $450 \mu \mathrm{U} / \mathrm{ml}$ $(172 \pm 52)$, and urinary 17-ketosteroid excretion $25 \mathrm{nmol} /$ day (33 to 69). Testicular biopsy revealed atrophic seminiferous ducts and tubules without any sign of spermatogenesis.

Cytogenetic studies indicated that the patient had

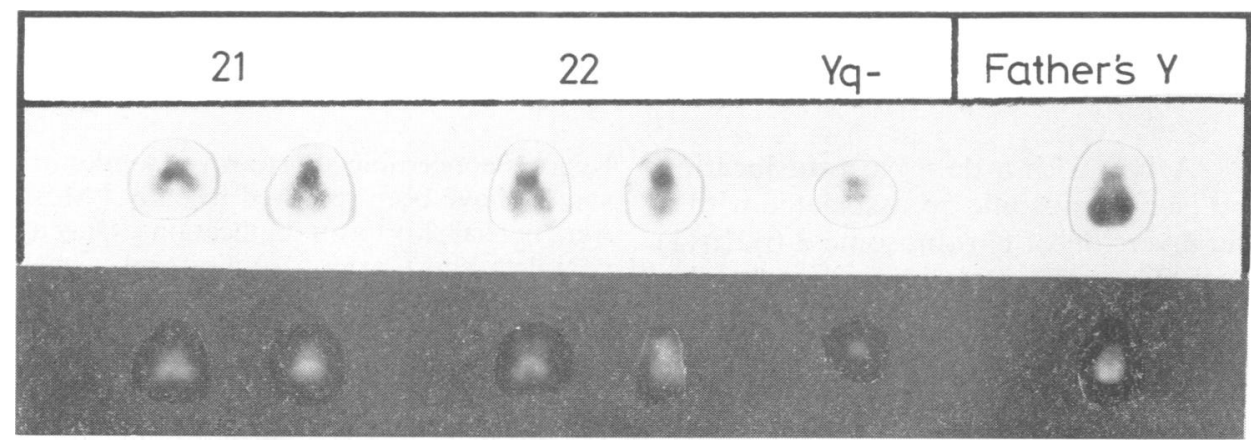

FIGURE Partial $C$ and $Q$ banded karyotype of the proband and Y chromosome of the proband's father. 
a karyotype of $46, X, \operatorname{del}(Y)(q 11)$. The deleted $Y$ had neither $\mathrm{C}$ positive nor brightly fluorescing bands (figure). The $\mathrm{Y}$ chromosome of the proband's father was normal in appearance.

\section{Discussion}

The amount of the missing part of the $\mathrm{Yq}$ in our case is difficult to judge. However, evaluating the cytogenetic findings, and comparing the patient's phenotype with the karyotype-phenotype correlations published so far, ${ }^{1-3}$ indicate that some of the euchromatic Yq must have been deleted together with the heterochromatin. The patient has small stature and failure of spermatogenesis which indicates that growth promoting factors and genes for spermatogenesis are located close to each other on the deleted segment of Yq, adjacent to the heterochromatin. The patient's male phenotype indicates, in agreement with published cases, that the primary inducers of maleness exist on the non-deleted portion of the $\mathrm{Y}$ chromosome.

Very little is known about the psychotic character of patients with deleted Yq. Kato et $a l^{4}$ described a schizophrenic man of normal phenotype who had a small $\mathbf{Y}$ chromosome; however, neither $\mathbf{C}$ nor $\mathbf{Q}$ banding was done. Since psychotic disorder is not a common symptom in such cases, a direct connection between the $\mathrm{Yq}$ deletion and the schizoid character disorder observed by us is questionable. The hypothesis of Forssman, ${ }^{5}$ namely that gonosomal 'imbalance' in general causes cerebral dysfunction favourable to the development of psychosis, may offer an explanation. However, the neonatal resuscitation performed in our case must be taken into consideration as well, since perinatal asphyxia is known to cause 'minimal brain damage' which is also favourable to the development of psychosis. To decide whether or not psychotic disorders are accompanying features of $\mathbf{Y q}-$ cases, together with small stature and abnormal male sexual differentiation, further karyotype-phenotype correlations are needed.

\section{References}

1 Bühler EM. A synopsis of the human Y chromosome. Hum Genet 1980;55:145-75.

2 Tiepolo L, Zuffardi O. Localization of factors controlling spermatogenesis in the non-fluorescent portion of the human Y chromosome long arm. Hum Genet 1976;34: 119-24.

3 Yunis E, Garcia-Conti FL, Torres de Caballero OM, Giraldo A. Yq deletion, aspermia, and short stature. Hum Genet 1977;39:117-22.

4 Kato T, Takagi N, Morita S. A chromosome study in seven neuropsychiatric patients, with special regard to the abnormality of the Y chromosome. Jpn J Genet $1965 ; 40$ : 105-12.

5 Forssman $\mathrm{H}$. The mental implications of sex chromosome aberrations. Br J Psychiatry 1970;117:353-63.

Correspondence and requests for reprints to $\mathrm{Dr} \mathrm{G}$ Kosztolányi, Department of Pediatrics, University Medical School, 7623 Pécs, Hungary.

\title{
Complete trisomy $5 \mathrm{p}$ owing to de novo translocation $\mathrm{t}(5 ; 22)(\mathrm{q} 11 ; \mathrm{p} 11)$ with isochromosome $5 p$ associated with a familial pericentric inversion of chromosome 2, inv 2(p21q11)
}

\author{
E ORYE, Y BENOIT, AND B VAN MELE
}

Laboratory of Cytogenetics, Department of Pediatrics, Akademisch Ziekenhuis, Rijksuniversiteit Gent, Gent, Belgium.

SUMMARY A boy with a de novo translocation $(5 ; 22)$ and isochromosome $5 p$ associated with a pericentric inversion of chromosome 2 (p21q11) is described. The pericentric inversion was also present in the mother. The main clinical features of the 'complete trisomy 5p' syndrome were present in the proband.

Received for publication 10 March 1983. Accepted for publication 31 March 1983.
Reports concerning short arm trisomies of chromosome 5 have been reviewed recently. ${ }^{1}$ Most of them were partial short arm duplications. Only a few were complete short arm trisomies and a new case is reported here.

\section{Case report}

The proband was born at term after an uncomplicated pregnancy. Birthweight was $3000 \mathrm{~g}$. He was 